\title{
Challenges and Opportunities Constraining and Enhancing Kenya and Tanzania Participation in the EAC Econo-Political Integration Process
}

\author{
J. P. Wakhungu, G. P. Okoth, E. O. S. Odhiambo \\ Department of Peace and Conflict Studies, Masinde Muliro University of Science and Technology, Kakamega, Kenya \\ Email: juwakhungu@gmail.com, pontianokoth@yahoo.com, eodhiambo@mmust.ac.ke
}

How to cite this paper: Wakhungu, J. P., Okoth, G. P., \& Odhiambo, E. O. S. (2021). Challenges and Opportunities Constraining and Enhancing Kenya and Tanzania Participation in the EAC Econo-Political Integration Process. Open Journal of Political Science, 11, 134-154.

https://doi.org/10.4236/ojps.2021.111009

Received: December 17, 2020

Accepted: January 22, 2021

Published: January 25, 2021

Copyright $\odot 2021$ by author(s) and Scientific Research Publishing Inc. This work is licensed under the Creative Commons Attribution International License (CC BY 4.0).

http://creativecommons.org/licenses/by/4.0/

(c) (i) Open Access

\begin{abstract}
Regionalism and regional institutions are increasingly being challenged and conditioned by the sovereignty-modifying effects of globalisation and humanitarian intervention. Regionalism is facing pressure to become less sovereignty-bound in the sense of going against the norms of non-interference and non-intervention that underpin the Westphalia international system. The study evaluates the challenges and opportunities that constrain and enhance Kenya and Tanzania participation in the EAC econo-political integration process. Three theories, Two-Good theory, Neoclassical Realism and Neo-functionalism theories, were adopted to guide the study. Descriptive research design was used. Respondents were both from Kenya and Tanzania and they comprised cross border business community, government officials in Ministries of EAC and Foreign Affairs, and EAC organs-the Secretariat and Legislative Assembly which were purposively sampled. Both primary and secondary sources data was used while instruments of data collection were: questionnaires, interviews and focus group discussions guides. Findings revealed that challenges that constrain Kenya's and Tanzania's participation in the EAC integration emanate from structural, legal and administrative weaknesses and commissions or omissions. The fact that the issue of manifestation of non-tariff barriers disguised as administrative and technical policies is baneful and inimical. Additionally, import substitution strategy and the incongruity in taxation policies are some of the challenges that constrain Kenya's and Tanzania's participation in the EAC econo-political integration. The study therefore recommends that the citizens should be at the centre of the EAC integration process through structured stakeholders' engagement where their input and participation are affirmed. Similarly, taxation of cross border business community should be reviewed and taxes should be harmonised to provide a level playing field in order to address their perennial complaints.
\end{abstract}




\section{Keywords}

Construct, Discombobulate, Econo-Political Integration

\section{Introduction}

The fervour for regionalism is etched in the minds of the political class globally. Some advocate for continental integration while others call for regional groupings that consist of few states whose defining criterion is territorial contiguity. The success story of European regionalisation experiment has been cited as a factor that has inspired the recent wave of regionalism (Masinde \& Omolo, 2017). The European Union (EU) is considered as the centerpiece of resurgent regionalism. Today, neither economics nor peace serves as the main buttress for justifying further integration. These justifications have given way to the idea that the EU is necessary by virtue of its contribution to international politics (Bickerton, Egan, Nugent, \& Peterson, 2015). In Africa, during the past years, the need to provide solutions to Africa's numerous political and economic problems has led to the initiation of various regional integration programmes (Fagbayibo, 2012).

As states march on into labyrinths of regional projects, the role of foreign policy and diplomacy tends to be regrettably an afterthought. It has to be reaffirmed that at the heart of states' interaction in regional and global settings, foreign policy occupies a significant position. Okoth (2010) defines foreign policy as the sum total of the principles, interests and objectives which a given state formulates in conducting its relations with other states. Foreign policy is thus understood as "a set of goals, directives or intentions", formulated by persons in official or authoritative positions, directed at some actor or condition in the environment beyond the sovereign nation-state, for the purpose of affecting the target in the manner desired by the policymakers' (Cohen \& Harris, 1975). The observation submitted by Williams (2004) regarding how foreign policy is avidly conceived and sourced is worth mentioning. He observes that foreign policy is not made in a political vacuum but is shaped by domestic factors, globalizing measures, integrative tendencies and transnational forces. Foreign policy is the content of foreign relations, comprising the aspirations and aims, which a country wants to achieve in its relations with other states and inter-governmental organizations (Kleiner, 2009).

The EAC Partner States are almost unable to control the pace of integration. The Customs Union has achieved some level of implementation including institutionalisation of the common external tariff regime and single customs territory among others. Similarly, as alluded to by Cichecka (2018), certain aspects of the Common Market have been implemented with mixed results. Whereas the Common Market has led to increased intra-EAC trade, however, specific provisions of it in regard to enhancement of regional integration have not been im- 
plemented or are facing severe bottlenecks. Critical steps including cross border movement of capital, free movement of labour, the rights of establishment and residence are yet to be realised in full. The questions that ought to be investigated are: why is it that EAC Partner States have consistently failed to implement their commitments in regard to certain aspects of EAC integration? Could all these be as a result of national policies and interests? Could the EAC econo-political journey be the victim of hostile, immutable and insular foreign policies of Partner States? It is against this background that the resolve to undertake this study crystallized.

\subsection{Statement of the Problem}

The stability of East Africa depends on the two states since similar geopolitical factors are active in their milieus; and the challenges that constrain their participation are self-inflicted and arise from structural, legal and administrative deficits. Econo-political integration that transcends national territory is difficult to attain. It, therefore, behooves members to possess the necessary dazzling honesty to integrate regional interests in their policy portfolios. One of the policy areas that demonstrate a state's gravitas toward a regional cause is its foreign policy. However, foreign policy choices of some EAC member states call into question their fidelity to regionalism. The fundamental question that was investigated in this study is, the challenges that foreign policies of Kenya and Tanzania face in acceleration or impeding of EAC econo-political integration?

Kenya signed and ratified it while Tanzania has not and is regarded as its main opponent (Pichon, 2018). Additionally, there is concern about the nature of multiple memberships by EAC states to a number of other regional blocs; Rwanda, Burundi, Kenya and Uganda are members of COMESA while Tanzania belongs to SADC. This situation has contributed to divergent positions on crucial global issues (Okuthe-Oyugi, 2012). Given that Tanzania adopted capitalist mode of production in tandem with Kenya's milieu, to what extent do their foreign policy predispositions complement and reinforce regional integration and identity? It is in this regard that this study was envisaged.

\subsection{Objective of the Study}

The objective of the study was to evaluate challenges and opportunities constraining and enhancing Kenya and Tanzania participation in the EAC econo-political integration process.

\subsection{Research Question}

Which challenges and opportunities affect Kenya and Tanzania participation in the EAC econo-political integration?

\subsection{Justification of the Study}

\subsubsection{Academic Justification}

The study will be useful in informing an academic discourse on the vitality of 
foreign policy in creating or deconstructing the narrative that has been around for a while that developing countries possess on a common foreign policy platform to grant them political wherewithal in multilateral settings. This dimension is what had not been exhaustively studied. In this regard, the findings will further provide lessons to scholars of international relations on the importance of foreign policy as leverage in coalescing regional groupings and conferring on such states the necessary international political legitimacy.

\subsubsection{Policy Justification}

The study will serve as a point of reference in strengthening regional economic and political integration process and commitment to a mature unified foreign policy platform ensconced in a structure that is predictable, certain and intelligent to the policymakers. The study will further serve as an important source of knowledge undertaken to examine the influence of member states' foreign policy behaviour on a regional grouping and its proclivity in coalescing states to collectively pursue mundane national interests in the external environment.

\subsubsection{Philosophical Justification}

Foreign policy is conceptualized, influenced and shaped by society. Foreign policy is a product of conceptualisation by the ruling class to affect desired philosophical thrust in the external environment. Therefore, to understand the principles that characterise conceptualisation of political choices by actors, it becomes imperative to investigate their worldview to sensationally appreciate the logical basis that inform subtle manoeuvres that lie at the core of decision making processes.

\section{Economic and Political Integration Challenges and Opportunities}

States are rushing into regional groupings to benefit from cooperation which is in tandem with pursuit of national interests in pluralistic approach under the banner of multilateralism. Regionalism is about interstate relations and cooperation therefore the role played by politics cannot be overemphasised. Genna and Hiroi (2015) confirm the political thread of regional integration. They argue that if parties to a regional integration organisation are to reap the fruit of integration, political stability is necessary, hence regional integration and politics are intertwined and affect each other in equal measure.

\subsection{Economic and Political Integration Challenges}

Schiff and Winters (2003) examine the nexus between regional integration and development and note that there is a close correlation between the two. They eloquently articulate a historical account of the origin of regional integration and submit that it has layers with the top layer being shallow integration and the deep nature of regional cooperation referred to as deep integration. It is observed by these scholars that regional integration permeates every country exist- 
ing in the international system and that its benefits are far-reaching particularly to less developed countries. However, the critical point that Schiff and Winters bring out in their work is the fact that regional integration agreements around the world are part of the protectionist, discriminatory strategies. This assertion that regional integration projects at the beginning were characteristically protectionist and determinative is rejected by Haynes. Haynes (2005) believes that regionalism is not about protectionism but rather it reinforces globalisation and benefits from the same and that states enter into regional groupings to gain "economies of scale" in multilateral arrangements. Schiff and Winters further observe that regional integration agreements have had tremendous impact on structuring of politics.

On the other hand, these regional blocs have been influenced to a greater degree by politics. Schiff and Winters submit that “...no economic analysis of a regional integration agreement is complete without taking the potential welfare benefits of the political objectives into account". Their submission is informative and congruent to the objectives of this study but it does not explicitly address in sufficient detail how politics and regional integration complement one another. Neither did they demonstrate with sufficient certainty the link between regional integration and foreign policy. It is true that the nuances on interstate relations is embedded in their work, however, this does not cure the shortcomings of determining the influence that foreign policy predispositions of individual member states have on econo-political integration process of a regional project.

Severino (2006) writing on the political status of ASEAN, acknowledges that it is founded on personal relations and strong bonds of brotherhood and solidarity among leaders of the region. He observes that ASEAN's first priority is political agenda as it seeks to strengthen peace and security as a guarantor of stability and economic development. Severino posits that the fabrics of ASEAN regional bloc are unique in that it does not rely on institutions and formalised structures to advance its agenda. It is a rather loose arrangement blended with personal ties and diplomatic skills. As earlier noted the centrality of ASEAN integration agenda is security and regional stability. Severino's observation is important to this study and challenges scholars who believe that regional integration or any other international grouping should be based on formalised structures and treaties. This study endeavoured to assess how foreign policy predispositions of individual member states can influence a regional project's econo-political integration process. Severino's observation that politics is an important ingredient in holding ASEAN together and that ASEAN states are good at promoting interstate relations to achieve its desired goals goes to the heart of this study. Indeed, in Severino's account, there is a nexus between political integration and interstate relations. The two influence each other and cohabit in a seamless manner. Regional integration benefits from interstate relations and in any case for a state to opt to join a regional bloc it must be that the decision is part of its foreign policy priorities. Therefore, Severino's submission regarding ASEAN as a regional bloc informed this study on the need to assess the influence of foreign 
policy in a regional integration setting. Admittedly, there is a clear and an unambiguous congruence between foreign policy and integration as submitted by Severino. However, beneath his submission, there are severe challenges in creating harmony and parsimony among foreign policies of individual members of a given regional bloc. This is informed by the reality that foreign policies are based on ideologies, predispositions, idiosyncrasies and rivalry with specific predisposition of attaining the so called national interest. Therefore, to attempt to coordinate and compress foreign policies of sovereign states into one ornate compendium is difficult, challenging and in most cases impossible.

In his submission regarding the ubiquitous desire for Arab unity, Hudson (1999) notes that integration in its purest form; cannot be attained in the Arab world due to anarchy, despair, chaos and instability. He argues that integration as we conceptualise it; is a cherished dream that cannot be realised in the Middle East. The Arab disunity and the propensity to violence, mistrust and suspicion have conspired to sow seeds of discord that have allowed external actors to manipulate the Arabs for selfish interests. This is the reality despite the fact that there is an unfailing verve for integration which exists in the Arab psyche. To this end, Hudson proposes that due to the poisoned political atmosphere in the Arab world another variant of integration may be suitable to their circumstances but not integration as conceptualised by scholars and practitioners. Hudson expresses an opinion that was relevant to this study. It is fair to argue that politics have direct correlation with integration. In fact, integration is driven by politics as it is a political process. Therefore, in circumstances where there is no goodwill, integration cannot thrive. Similarly, the type and the level of integration that a region may adopt depend solely on the politics of the day. This understanding is necessary in appreciating the difficulties that beset states when cohabiting in a regional grouping. In any case integration is a voluntary enterprise and a state may opt not to join any regional grouping if that serves its interests better. The issues advanced by Hudson regarding Arab politics are the same issues that impede advancement of deep regional integration in Africa. These issues are ubiquitous and their propensity in disorienting a regional grouping's econo-political agenda cannot be wished away.

Caporaso (2000) looks at the dilemmas of regional integration from the $\mathrm{Eu}$ ropean Union (EU) point of view. He holds that there are dilemmas confronting the EU in its external relations. These dilemmas include the relationship of Europe to the outside world (open versus closed); the relationship between widening and deepening Europe's capacity to construct a common foreign and security policy without member states relinquishing their sovereignty. These among others are vexing challenges that the EU has to address in an effort to promote and sustain regional integration. He cautions that in the context of the European integration, the term external can refer first to the foreign relations and activities of the member states, or the relations of the EU considered as an entity, to other state and non-state actors around the world. The dilemma in the construction of a common foreign and security policy regards trade-off between creating a 
common foreign policy, and thus presumably having greater collective impact, versus each state giving its individual way and retaining autonomy. He further argues that in an environment of intense interdependence, a state will have to choose between less effective policies that preserve sovereignty and common policies that sacrifice it.

Acharya (2002) gives an assessment of regionalism and contrasts it with sovereignty, autonomy and identity. He argues that regionalism and regional institutions are increasingly being challenged and conditioned by the sovereignty-modifying effects of globalisation and humanitarian intervention. He asserts that regionalism is facing pressure to become less sovereignty-bound in the sense of going against the norms of non-interference and non-intervention that underpin the Westphalia international system. He further asserts that intrusive regionalism is providing a new basis for regional identity building especially in Europe. His submission is that the new regionalism as opposed to the earlier one is constructed on the basis of a shared commitment to intrusive action in promoting human rights and democracy and coping with the challenges of economic globalisation. States enter into regional groupings being first sensitive of their sovereignty and if the same is likely to be challenged as a consequence, then the chances of states defecting from regional integration projects are very high.

Ouchi (2013) discusses a myriad of challenges associated with free movement of capital in the EAC. He argues that there are several macroeconomic challenges that negate convergence in regional integration and to which the EAC is by no means invulnerable. He enumerates the challenges to include multiple memberships in Regional Economic Communities (RECs) that makes the states within the blocs to compete with one another rather than complement each other. This undermines efforts for harmonisation and coordination, resulting in wasteful duplication of constrained resources. Ouchi (2013) further laments that slow ratification of protocols as well reluctant implementation of agreed plans due to; a lack of political commitment; a lack of perceived or real losses and sacrifice; a lack of cost benefit analyses of integration programmes to be implemented and changes in the socioeconomic and political dynamics impacts deleteriously on the integration process. He observes that the socio-economic policy divergence or policy incoherence creates problems for the systematic implementation and "internationalisation" of the regional agenda into national programmes. He further observes that these together with national and regional incapacities exist in the form of a lack of mechanisms and resources for effective planning, coordination, implementation, monitoring, and pragmatic adjustments of programmes on the ground. Ouchi's postulation speaks to the core objective of this study. The challenges as enumerated by Ouchi were aptly salient to the thrust of this study.

\subsection{Economic and Political Integration Opportunities}

Koné (2012) seeks to make a distinction between economic and political integra- 
tion. He observes that economic and political integration differ in their frames, objectives, and mechanisms. In this regard, he asserts that economic integration has the framework of the economy. It primarily seeks to liberalise the trade exchanges, between partners in order to improve the overall efficiency and to develop the economies of the partner countries. On the other hand, Koné (2012) sees political integration as having the frame of management of power or the administration of the city. In its international dimension, he argues, it consists of transferring the exclusive rights of the state-nations to a broader political entity. In this regard it aims at building more effective political entities. His reassuring statement is that an economic integration cannot be done without a political integration.

Roberts (2017) discusses in general economic challenges bedeviling Africa's development. He submits that on the one hand regional integration is essentially viewed as removing tariff and non-tariff barriers to trade; in essence, second-best to unilateral liberalisation. He further observes that regional integration is also advocated as part of defragmenting Africa, overcoming the legacy of colonial borders, adding the reduction (or removal) of border controls to the agenda of tariff liberalism. He asserts that given the scale of economies and relatively small national markets, firms make decisions across countries.

Discussing ASEAN, Kojima and Bengtsson (2015) assess the benefits presented by this regional integration project. They allude to the fact that regional integration processes in the Asia-Pacific region mainly emphasises market liberalisation (regional economic integration) as a means to increase economic growth. This implies that regional integration provide economic opportunities to participating states. However, they caution that blind pursuit of economic integration may trigger unnecessary competition which may damage the environment. They regard regional integration as an important process and means of coordinating efforts to make it easier for countries to formulate and implement more balanced and sustainable models for development.

Intal (2018) postulation in regard to the importance and the opportunities presented by economic and political integration is sufficient and lucidly clear. The issue of security emerges in his submission as small and middleweight states in a regional grouping are supported by big powers and are able to find the security space in a regional grouping. Intal (2018) argues that the regional integration architecture has benefitted in East Asia due to copious security.

\section{Conceptual Framework}

Wasike and Odhiambo (2016) discuss the role of theories in guiding the thrust of academic studies. They emphasise the importance of theories in offering compelling and incisive causal explanations with calculated precision. They buttress their argument by quoting Smith (1996) who asserts that theories play the role of predicting, prescribing and evaluating socio-political phenomena hence they cannot be ignored. 


\subsection{Summary of Theories}

This study adopted three theories. The Two-Good theory of foreign policy-Palmer and Morgan (2006), Neoclassical Realism-Thomas, 1996; Randall, 1998; William, 1993 and Fareed, 1998 in (Rose, 1998) and Neo-functionalism-Ernest Haas; Leon Lindberg and Phillipe Schmitter (O'neill, 1996). The Two-Good theory seeks to explain the intrinsic reasons that motivate states to pursue specific foreign policy goals. States essentially pursue two things namely change and maintenance through their international behaviour. The central argument of Neoclassical Realism is that relative material power establishes the basic parameters of a country's foreign policy and that foreign policy is best understood as the product of a country's internal dynamics. Neo-functionalism sees states as culturally insular, hence incapable of meeting more expansive functional or welfare needs of modern citizens. This can only be met by international cooperation. The theory sees political integration as the process whereby nations forego desire and ability to conduct foreign and key domestic policies independently of each other (Wolforth, 2012).

\subsection{Conceptual Model}

Figure 1 shows the interaction of the variables. The independent variable is foreign policy predispositions. The immutable elements of foreign policy in any state are national goals and interests that states pursue in the external environment. Foreign policies are shaped by domestic and international politics. The dependent variable is the EAC econo-political integration. Therefore, this study

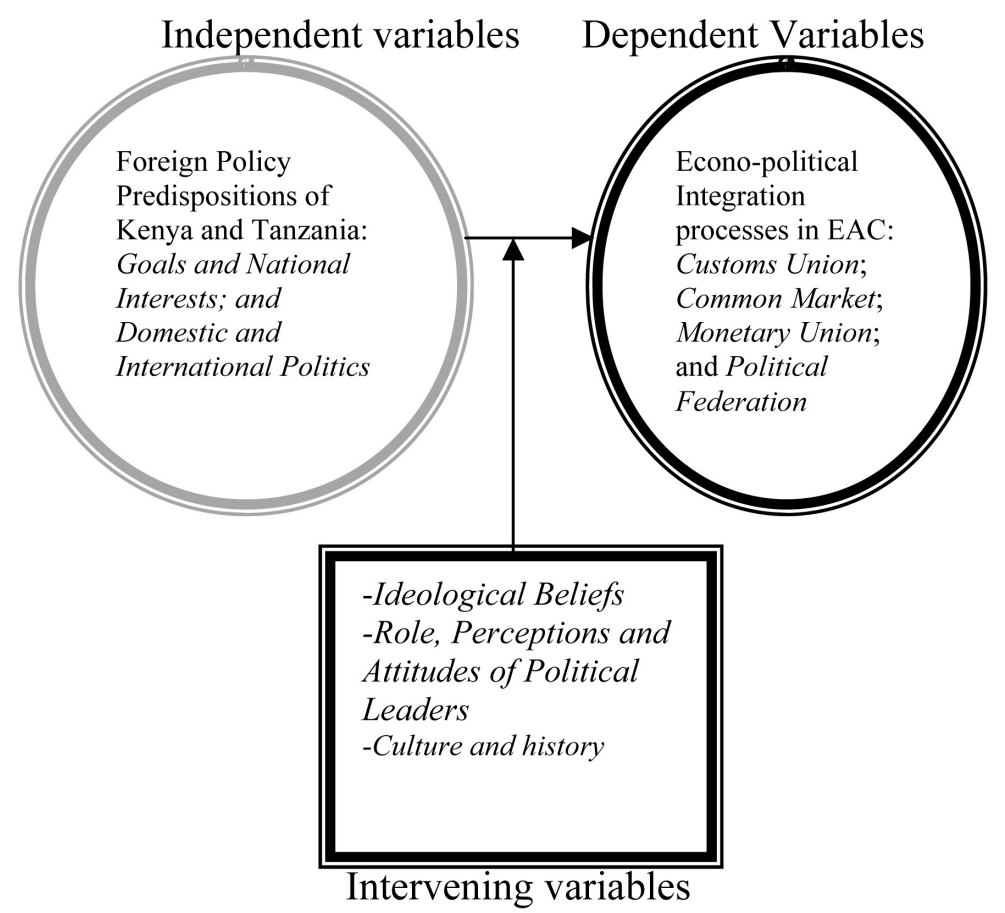

Figure 1. Conceptual model framework showing interaction of variables. Source: Researchers, 2020. 
sought to determine the extent to which the independent variable influence the EAC econo-political integration taking note of the elements of EAC econo-political integration process which are ensconced in the integration pillars. The pillars are: Customs; Common Market; Monetary Union and Political Federation (EAC Treaty, 2006). The Conceptual Model Framework illustrates the link between the independent and the dependent variables. However, the impact is moderated by intervening variables. The intervening variables that have causal link between foreign policy predispositions and EAC econo-political integration process include: ideological beliefs; role, perceptions and attitudes of political leaders; culture and history.

\section{Research Methodology}

\subsection{Research Design}

Cross-cultural design was used in the study to compare and contrast foreign policy pillars of the two states and evaluate how they have influence EAC econo-politcal integration process. This study sought to discover the underlying factors that influence both the independent and dependent variables hence the exploratory design was chosen as ideal in attaining this goal. Kumar (2014) further reinforces the value of adopting qualitative designs by opining that the main focus in qualitative research is to understand, explain, discover and clarify situations, feelings, perceptions, attitudes, values, beliefs and experiences of a group of people.

\subsection{Study Area}

The study was carried out in Kenya and Tanzania. The two are member states of the East African Community and are its core founder members with shared historical, political and social heritage making them ideal for the research. They share contiguous ethnic compositions, cross border social affiliations, geography, cultural affinity, colonial heritage and trade relations. These states wield preponderant influence in EAC compared to the other four, namely Uganda, Rwanda, Burundi and South Sudan and, therefore, the findings accruing from the study can generally be applied across the board. In view of the complexities involved in collecting, collating and interpreting data, the other four member states of EAC were not be covered in the study and this did not in any way affect the reliability or validity of the findings (Figure 2).

\subsection{Sampling Strategy}

The study adopted a purposive sampling strategy due to the nature of interpretive paradigm denoting the necessity of seeking respondents' opinions and corroborating them to examine insights and issues that are critical and pertinent to the study's objective. The justification for purposive sampling is aptly captured by Patton (2002) who argues that the logic and power of purposeful sampling lie in selecting information-rich cases for study in depth. 


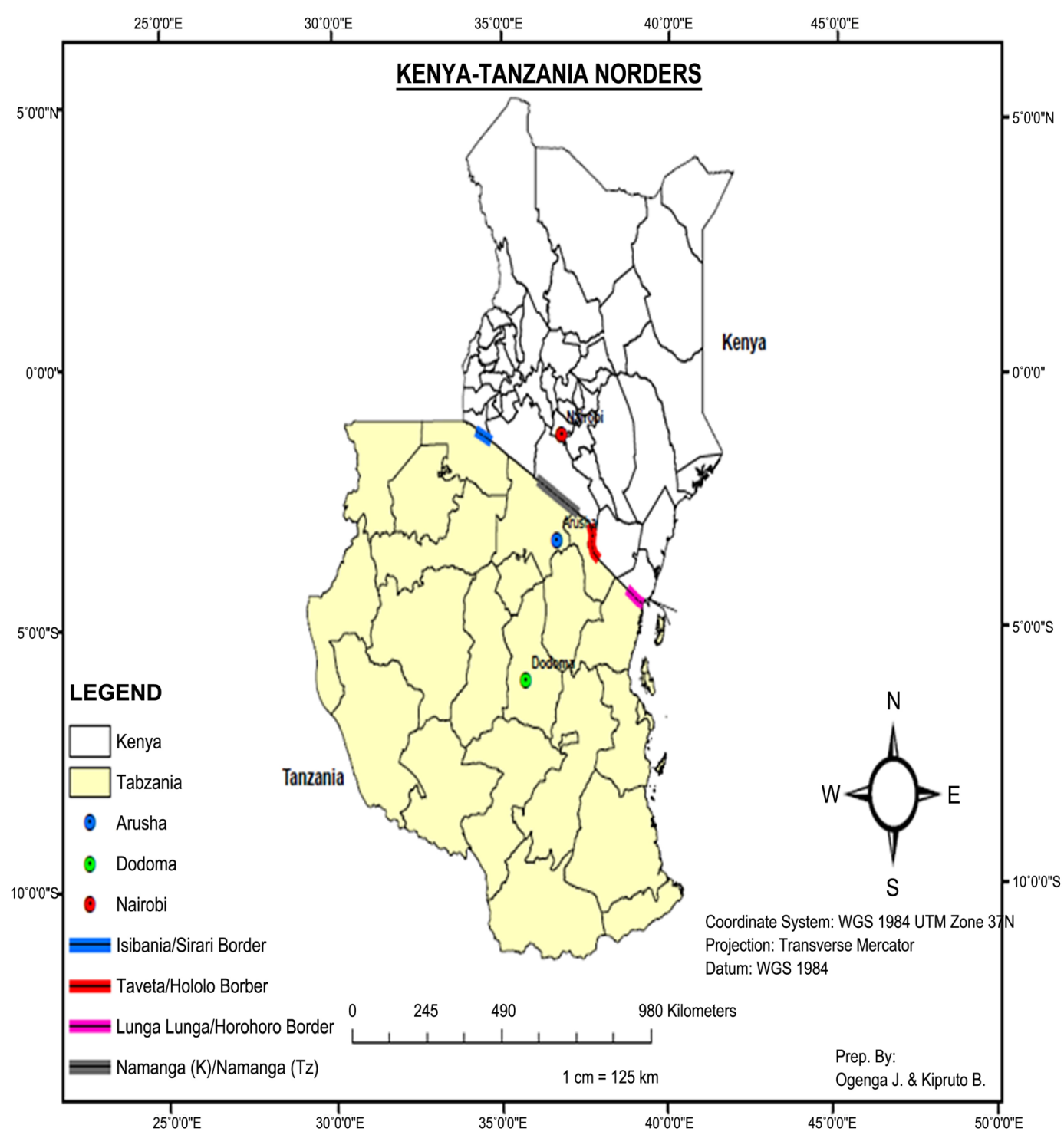

Figure 2. Study area-Kenya and Tanzania. Source: Researchers, 2020.

\subsection{Sample Size}

The study population as already noted was citizens of Kenya and Tanzania. Given the massive combined population of the two states which is approximately 103 million, it was not possible to practically cover every one. In this regard, the researcher adopted the recommendation provided by Gomm (2008). Gomm (2008) prescribes a formula of determining appropriate sample sizes. He proposes that for a population of 50,000 individuals, the required sample size is 381 items. He goes on to propose that a population of size of $1,000,000$ or more, the ideal sample size is 384 . The same recommendation is made by Mugenda and Mugenda (2003). It was established that persons and entities that have direct stakes in the EAC integration process and who could be valuable to the study are government officials working in Ministries of Foreign and East African Community affairs, officials in the EAC Organs-the Secretariat and East African 
Legislative Assembly and cross border business community who operate at the borders and in Partner States. In this regard, the study purposefully covered cross border business community at major points of entry between Kenya (173) and Tanzania (181); government officials in the two states which perform diplomatic and administrative duties in Ministries responsible for EAC and Foreign Affairs (20); and EAC Secretariat (6) and the Legislative Assembly (4).

\subsection{Data Collection Methods}

Questionnaires, interviews and observations, government documents, video, tapes, newspapers, letters, and books were used (Corbin \& Strauss, 1990). Data was collected from two sources in the two countries. Primary data which was instrumental in answering the objectives of the study was obtained from the respondents in Kenya and Tanzania including key informants in government ministries and EAC organs. Secondary data formed an integral part of the study. Secondary data were obtained from sources in Kenya and Tanzania including the EAC Secretariat's Library, books, newspapers, government documents, journals, articles and archival materials.

\subsection{Data Analysis}

The data were analysed as per the dictates of scientific research. Qualitative data were first processed, summarised and categorised into appropriate themes. Content analysis was used to determine which themes occur most frequently, in what contexts and how they are related to each other (Patton, 2002). Data collected through questionnaires, interviews and focus group discussions were triangulated to ascertain their efficacy. On the other hand, quantitative data which are numeric in nature were analysed through descriptive analysis which comprises statistics describing, aggregating and presenting the constructs of interest. Inferential statistics arising from the findings were interpreted to reach conclusions about associations among variables. Charts, graphs, tables were used to project and compare scenarios and any other piece of information that can be best presented quantitatively.

\section{Findings}

Table 1, Figure 3 summarizes political challenges that affect Kenya's and Tanzania's participation in the EAC integration process as discussed and rated by the respondents. These challenges are diverse with varying degree of importance. The most conspicuous challenges adduced by the respondents are two-multiplicity of memberships and lack of political commitment by Partner states. It has to be clarified that multiplicity of memberships affects both Kenya and Tanzania and other EAC Partner States. Kenya in this regard belongs to EAC, COMSA and IGAD. On the other hand Tanzania belongs to EAC and SADC. The issue of multiplicity of memberships should not be condemned; rather it should be seen as part of statecraft and is guided by the national interest of a state in question. 
Table 1. Political challenges affecting participation of Kenya and Tanzania in EAC integration (percentage scores).

\begin{tabular}{|c|c|c|}
\hline 1. & Multiplicity of memberships. & $75 \%$ \\
\hline 2. & $\begin{array}{c}\text { Prolonged gratification process of protocols, acts and } \\
\text { other regional facilitating legal instruments. }\end{array}$ & $65 \%$ \\
\hline 3. & Lack of political commitment. & $75 \%$ \\
\hline 4. & EAC partner states constitutions. & $20.5 \%$ \\
\hline 5. & The implication of sovereignty. & $60 \%$ (Kenya-33\% and Tanzania- $67 \%$ \\
\hline 6. & Nationalism and prejudices. & $69 \%$ \\
\hline
\end{tabular}

Source: Field Data, 2020.

\section{Political Challenges}

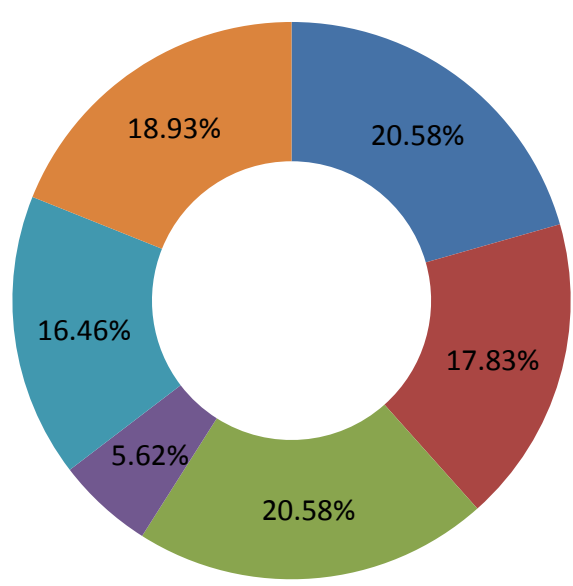

Multiplicity of memberships.

- Prolonged gratification process of protocols, acts and other regional facilitating legal instruments. - Lack of political commitment.

EAC partner states constitutions.

The implication of sovereignty.

Nationalism and prejudices.

Figure 3. Political challenges affecting Kenya and Tanzania participation in EAC. Source: Field Data, 2020.

Similarly, though the respondents indicated that lack of political commitment is a serious challenge bedevilling EAC in its aspiration to deepen the integration process, however, it is controversial. The issue of lack of political goodwill has no specific parameters that can be used to determine whether certain behaviour by Partner States can rightly be adjudged as lack of political commitment. Other challenges that affect the two Partner States include prolonged law ratification process, nationalism and prejudices, fear of loss of sovereignty, and Partner states' constitutions.

\subsection{Economic Challenges that Constrain Kenya's and Tanzania's Participation in EAC Integration}

EAC is a regional integration project anchored on the basics of sustainable economic development and shared prosperity. It derives its legitimacy from the people who regard it as a special purpose vehicle for transformation of the region into an economic hub through enhanced and copious trade transactions, sustainable value addition and supply chains and resilient manufacturing base. 
Article 5 (1 and 2) of the Treaty establishing EAC (EAC Treaty, 2006) states the objectives of the Community. The point to note is the economic theme that runs through the overall objective:

The objectives of the Community shall be to develop policies and programmes aimed at widening and deepening co-operation among the Partner States in political, economic, social and cultural fields, research and technology, defence, security and legal and judicial affairs, for their mutual benefit $(5,1)$. In pursuance of the provisions of paragraph 1 of this Article, the Partner States undertake to establish among themselves and in accordance with the provisions of this Treaty, a Customs Union, a Common Market, subsequently a Monetary Union and ultimately a Political Federation in order to strengthen and regulate the industrial, commercial, infrastructural, cultural, social, political and other relations of the Partner States to the end that there shall be accelerated, harmonious and balanced development and sustained expansion of economic activities, the benefit of which shall be equitably shared $(5,2)$.

This quotation from EAC Treaty (2006) affirms the fact that the Community is determined to accelerate economic development of the region for the benefit of its citizens. The Community aspires to deepen integration in the economic sector in order to unleash the necessary momentum that will ensure that the integration efforts are beneficial to the people of East Africa. Based on this quotation, the integration process as envisaged by the treaty is linear and gradual. The treaty envisages a Customs Union, a Common Market, subsequently a Monetary Union and ultimately a Political Federation. This linear approach is at times problematic and the process can get stuck at one stage for a long time to the extent that progress toward other integrative stages is brought to a complete halt. The linear model of regional integration is well captured in the treaty that establishes EAC (2006).

Therefore, the economic challenges that depress Kenya's and Tanzania's effective participation in the EAC econo-political integration go against the agreed principles and common understanding in regard to how the region should integrate economically. The policies of the two EAC Partner States with respect to treatment of each other's entrepreneurs, non-tariff barriers to trade, import substitution, East African Monetary integration, external actors interference, taxes, hidden costs of doing business, technical and administrative requirements that amount to trade non-tariff barriers, price differentials, documentation requirements, border controls and enforcement of border clearance procedures were considered by the respondents as disproportionately inimical to economic integration of the two states and the entire region. Other challenges that have direct debilitating impact particularly on the cross border business community at border points are police harassment, extortion by the security agencies who forcefully demand for bribes and information gap. The economic challenges are serious and frankly ubiquitous with the propensity of escalating tension and 
misunderstandings between the two EAC Partner States. Prakash and Hart (2000) make a powerful statement with respect to the obstacles that deflate regional integration process. They argue that countries can potentially integrate if minimal institutional obstacles to cross-border economic flows are present. These impediments manifest in various forms: import and export tariffs, non tariff barriers, capital controls, barriers to foreign direct investment (FDI), technology transfer, and real estate transactions. Removing or diluting institutional obstacles therefore becomes a necessary condition for economic integration.

This is corroborated by Nduti and Odhiambo (2020) in their article, Effects of Smuggling of Food Commodities on Households in Busia Town, Kenya which found out that between Kenya and Uganda:

"Culture of Corruption Findings indicate that law enforcement officers openly demanded bribes from the local traders. Prominent business people, transporters and in other instances market traders willingly offered bribes to the police and customs officers in order to have their commodities moved across. This has enhanced the culture of corruption in the society and even in households since people have it on their minds that they have to bribe their way out. Hence smuggling has a corroding influence on state institutions given the systematic networks of corruption that have evolved in order to facilitate the illegal activity. This thus impacts negatively on the social morals of the household members".

Table 2, Figure 4 shows in summary economic challenges affecting Kenya's and Tanzania's participation in the East African Community integration. Manifestation of non-tariff barriers, disproportionate taxes and levies and policy asymmetry were ranked highly by the respondents. They were considered by the respondents to be the most serious challenges affecting participation of Kenya and Tanzania in the EAC economic integration. The second tier of challenges that affect participation of Kenya in the EAC economic integration according to the respondents' ranking are harassment and arbitrary arrests of members of cross border business community by agents of the state, cumbersome clearance procedures and import substitution policy. The last two challenges that affect Kenya's and Tanzania's participation in EAC which were considered by the

Table 2. Economic challenges (percentage scores).

\begin{tabular}{|c|c|c|}
\hline 1. & Non-tariff barriers. & $90 \%$ \\
\hline 2. & Import substitution policy. & $\begin{array}{c}\text { 70\% (Kenya-33\%, } \\
\text { Tanzania-67\%) }\end{array}$ \\
\hline 3. & EAC monetary integrations. & $55 \%$ \\
\hline 4. & Interference by external actors. & $45 \%$ \\
\hline 5. & Disproportionate taxes and local levies. & $92 \%$ \\
\hline 6. & Cumbersome and stringent cross borders rules and regulations. & $70 \%$ \\
\hline 7. & Harassment, intimidation and arbitrary arrests. & $84.7 \%$ \\
\hline 8. & Policy asymmetry on common trans-boundary challenges. & $95 \%$ \\
\hline
\end{tabular}




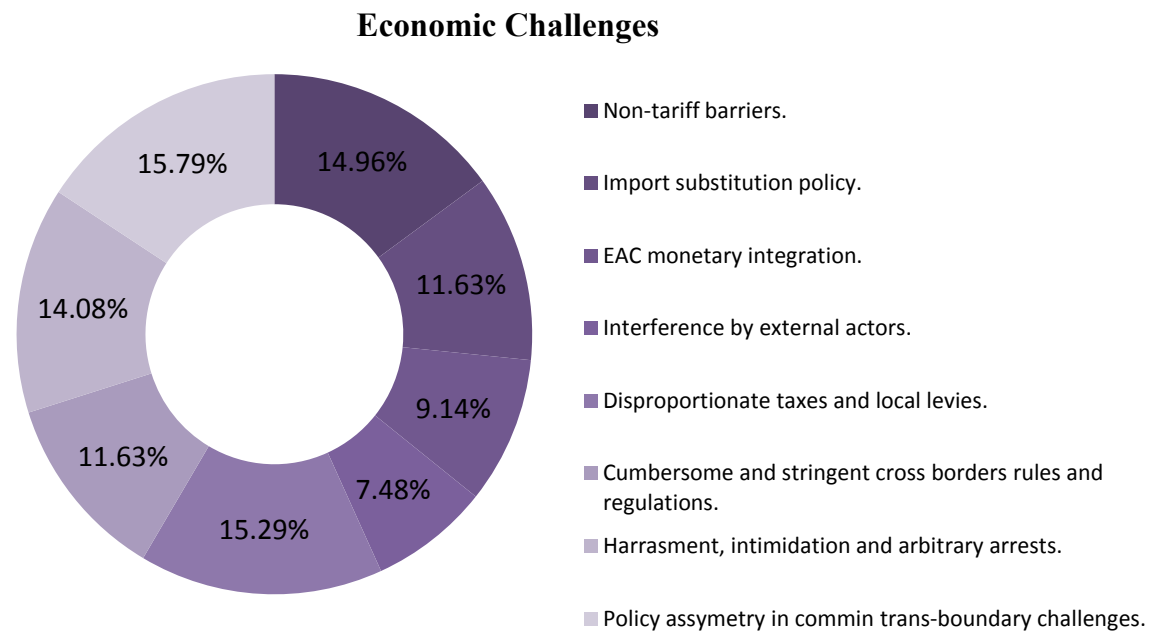

Figure 4. Economic challenges affecting Kenya and Tanzania participation in EAC integration. Source: Field Data, 2020.

respondents as not being so severe are lack of progress on the implementation of EAC Monetary Union and interference by external actors. Therefore, these challenges contribute to the slow pace of the integration process.

This is corroborated by Odhiambo et al. (2013) in their article, "Al-Shabaab Terrorists Propaganda and the Kenya government Response" when looking at the relationship between Kenya and Somalia found out that:

"Resorting to the Emotions Terrorist propaganda relies on a wide use of the emotional impact of certain visual material. Without any type of available or effective restriction, crude images of corpses and mutilations can be found on terrorist-sponsored sparse Web pages, including disabled persons and injured men portrayed as supposed evidence of the results of Kenya Defence Forces (KDF) military action. Terrorists are conscious that appealing to the emotions is one of the most rapid and effective ways of modifying public and personal attitudes, and they do not hesitate to resort to any type of material that they consider to be useful to this end".

Without committing to excesses, and always respecting ethical criteria, the Kenya counter-informative strategy cannot ignore the emotive perspective of this information war. Illustrating the results of terrorist action, through actual images of its victims and the resulting human tragedy, is one of the most powerful ways of delegitimizing terrorists. Together with respect due to the victims and their families, the exhibition of certain images can constitute a revolt against terrorists much more powerful than a long series of official communiqués regarding penalty. Indeed, concealing the real results of terror only helps to generate an idealised stereotype removed from what terrorism actually is".

\subsection{Opportunities that Enhance Kenya's and Tanzania's Participation in EAC Econo-Political Integration}

It is reiterated that EAC is an inter-governmental organisation integrating six 
member states economically, politically and socially. The legal framework cementing their strategic relations contains the treaty, protocols and acts of the East African Legislative Assembly. Economic and political integration is a resilient process that is shaped and influenced by endogenous and exogenous factors having direct impact on the evolution of the character and pace of regional integrative initiatives. However, challenges to the implementation of EAC policies agreed by member states remain. The 2014 EAC common market scorecard indicates that despite significant achievement, barriers to the movement of goods, services and capital still remains as a result of member state laws, regulations and capital controls, as well as membership in different RECs (EAC Report in Mathieson, 2016). Whereas there are challenges as submitted by the respondents in the foregoing section, however opportunities also abound. In order to develop a consistent pattern of analysis, economic and political opportunities that enhance Kenya's and Tanzania's participation in the EAC econo-political integration are mutually discussed taking note of their symbiotic nature. This corroborated by Odhiambo (2019) in his article "Character and Development Challenges and Opportunities Influencing Anglo-Kenyan Diplomatic Relations", where he argues that even KDF and BATUK relationship had resulted to economic challenge and opportunity not only for the soldiers themselves but also to the surrounding communities.

The symbiotic nature of economic and political integration is ably presented by Velde (2011). He posits that there are other roles for regional integration, beyond trade provisions. First, regions can support the provision of regional governance public goods. Effective international economic governance promotes economic development. He goes on to assert that some challenges are best met at the national or multilateral level, but some policymaking occurs at regional level in parallel with national policymaking. This assertion basically affirms the influence that politics has on economics and vice versa. Economics shapes politics and similarly politics shapes economics. Keech's (1991) philosophical assumption grounds this argument by developing a logical link between economics and politics. He asserts that the appeals of economic reasoning for political science include rigour, precision, and the absence of vagueness that often characterises political concepts, many of which are cluster concepts like politics itself.

In his justification, Keech (1991) proffers the general equilibrium theory, which is a theory of an automatic, equilibrating system. Within its own terms, an economy characterised by general equilibrium needs no central political direction or guidance. He goes on to proffer another theory of macroeconomic policy which is in its essence a theory about central direction, guidance, or control. It is a system that distils politics into the choice of the goals toward which the system is to be guided. The study assessed the political and economic opportunities that enhance Kenya's and Tanzania's participation in EAC econo-political integration. Some of the political and economic opportunities raised were: political goodwill; legal systems that support political integration; existence of EAC 


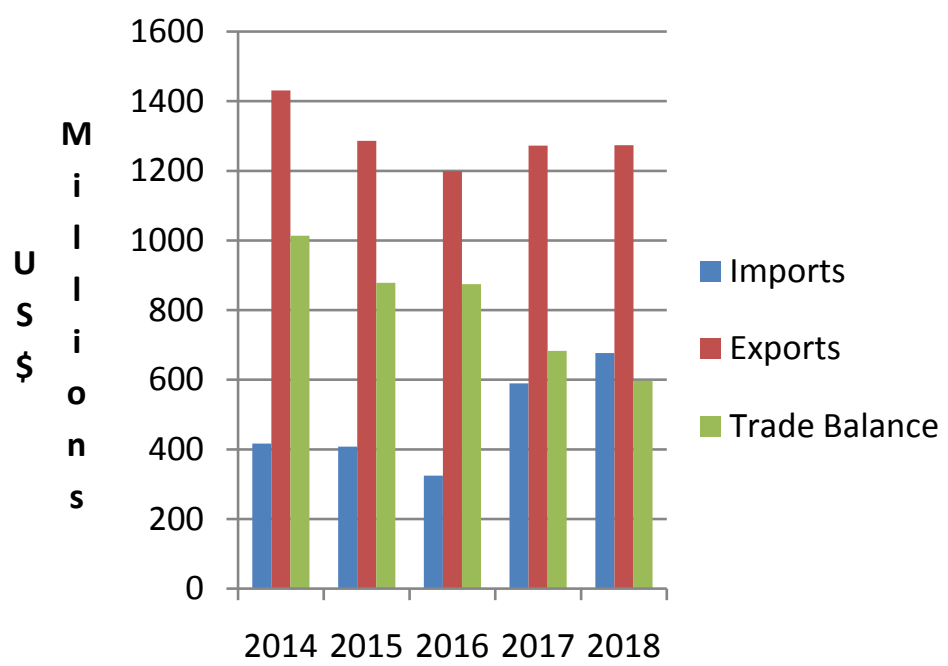

Figure 5. Trend of share of Kenya's intra-EAC trade from 2014-2018. Source: EAC Secretariat, 2018.

Customs Union and Common Market; discovery of fossil fuels in the region; and economic policy of liberalisation and deregulation.

From Figure 5 illustrates the trend of the share of Kenya's intra-EAC trade. The general observation is that Kenya exports more to the region than it imports. This is a clear indication that EAC is a very important region for Kenya's economic development. The most significant trading partners are Uganda and Tanzania. The intra-EAC trade balance is in Kenya's favour and this can only be attributed to the liberalised trading environment supported by the EAC Customs Union (EAC Single Customs Territory) and the EAC Common Market where trade policies have been harmonised in the region. Therefore, the availability of the Customs Union and the Common Market provide unique a opportunity for increased intra-EAC trade.

\section{Summary and Conclusion}

Challenges that constrain Kenya's and Tanzania's participation in the EAC econo-political integration emanate from structural, legal and administrative weaknesses and commissions or omissions. The fact that the issue of manifestation of non-tariff barriers disguised as administrative and technical policies is baneful and inimical. Additionally, import substitution strategy and the incongruity in taxation policies are some of the challenges that constrain Kenya's and Tanzania's participation in the EAC econo-political integration.

From the foregoing summary and conclusion, the study recommends that citizens should be at the centre of the EAC integration process through structured and multifaceted stakeholders' engagement where their input and participation are affirmed. Similarly, taxation of cross border business community should be reviewed and taxes should be harmonised to provide a level playing field in order to address their perennial and incessant complaints. 


\section{Conflicts of Interest}

The authors declare no conflicts of interest regarding the publication of this paper.

\section{References}

Acharya, A. (2002). Regionalism and the Emerging World Order: Sovereignty, Autonomy and Identity. In S. Breslin, W. C. Hughes, N. Phillips, \& B. Rosamond (Eds.), New Regionalisms in the Global Political Economy: Theories and Cases (pp. 20-33). Warwick: Routledge and Taylor and Francis Group. https://doi.org/10.4324/9780203361672_chapter_2

Bickerton, C., Egan, M., Nugent, N., \& Peterson, W. (2015). European Union Foreign Policy: From Effectiveness to Functionality. Palgrave: Macmillan.

Caporaso, J. (2000). The European Union Dilemmas of Regional Integration. Washington DC: Westview Press, University of Washington.

Cichecka, A. (2018). EAC-An Answer for Regional Problems or Failed Solutions in East Africa? Politeja (Ksiegarnia Akademika), 15, 267-277. https://doi.org/10.12797/Politeja.15.2018.56.15

Cohen, C., \& Harris, S. (1975). Foreign Policy. In F. I. Greenstein, \& N. Polsby (Eds.), Handbook of Political Science (pp. 89-111). Reading: Addison Wesley.

Corbin, J., \& Strauss, A. (1990). Grounded Theory Research: Procedures, Canons, and Evaluative Criteria. Qualitative Sociology, 13, 3-21. https://doi.org/10.1007/BF00988593

East African Community, EAC Treaty (2006). The Treaty for the Establishment of the East African Community, Arusha. Published by the EAC Secretariat.

Fagbayibo, B. (2012). Exploring Legal Imperatives of Regional Integration in Africa, the Comparative and International Law. Journal of Southern Africa, 45, 64-76.

Fareed, Z. (1998). From Wealth to Power: The Unusual Origins of Americas World Role (199 p). Princeton: Princeton University Press.

Genna, G., \& Hiroi, T. (2015). Do Democracy Clauses Matter? The Effects of Regional Integration Associations on Political Stability and Democratic Consolidation. EUI Working Papers: RSCA 2015/48, Florence: Robert Schuman Centre for Advanced Studies. https://doi.org/10.2139/ssrn.2631079

Gomm, R. (2008). Social Research Methodology: A Critical Introduction (2nd ed.). New York: Palgrave Macmillan.

Haynes, J. (2005). Comparative Politics in a Globalizing World. Malden: Polity Press.

Hudson, M. (1999). Arab Integration: An Overview. In M. C. Hudson, B. Korany, P. Noble, B. Tibi, M. K. Al-Sayyid, F. Heard-Bey, A. K. Abdulla, I. W. Zartman, R. D. Burrowes, R. Owen, Y. A. Sayyigh, \& N. Shafik (Eds.), Middle East Dilemma: The Politics and Economics of Arab Integration (pp. 1-23). New York: Columbia University Press.

Intal, P. (2018). East Asia: Transformation and Regional Architecture. In S. Armstrong, \& T. Westland (Eds.), Asian Economic Integration an Era of Global Uncertainty (pp. 235-258). Canberra: ANU Press. https://doi.org/10.22459/AEIEGU.01.2018.09

Keech, W. R. (1991). Politics, Economics, and Politics Again. The Journal of Politics, 53, 597-611. https://doi.org/10.2307/2131572

Kleiner, J. (2009). Diplomatic Practice, Between Tradition and Innovation. Singapore: World Scientific Publishing Co. PTE, Limited. https://doi.org/10.1142/7247

Kojima, S., \& Bengtsson, M. (2015). Greening Integration in Asia: How Regional Integra- 
tion Can Benefit People and Environment. From Report, Arlington, VA: Institute for Global Environmental Strategies.

Koné, S. (2012). Is Economic Integration between Developing Countries a Singular Process. Journal of Economic Integration, 27, 386-409. https://doi.org/10.11130/jei.2012.27.3.386

Kumar, R. (2014). Research Methodology (4th ed.). London: Sage Publications.

Masinde, W., \& Omolo, C. (2017). The Road to East African Integration. In E. Ugisrashebuja, E. J. Ruhangisa, T. Ottervanger, \& C. Armin (Eds.), East African Community Law (pp. 1-21). Brill Nijhoff: Institutional Substantive and Comparative EU Aspects (-Brill).

Mathieson, C. (2016). The Political Economy of Regional Integration in Africa: The East African Report. EAC Study (ECDPM), 1-74. http://www.ecdpm.org/peria/eac

Mugenda, M., \& Mugenda, G. (2003). Research Methods: Quantitative and Qualitative Approaches. Nairobi: Acts Press.

Nduti, D. M., \& Odhiambo, E. O. S. (2020) Effects of Smuggling of Food Commodities on Households in Busia Town, Kenya. International Journal of Scientific and Research Publications, 10, 18-33. http://www.ijsrp.org/research-paper-0520.php?rp=P1019959 https://doi.org/10.29322/IJSRP.10.05.2020.p10104

O'neill, M. (1996). The Politics of European Integration: A Reader. Abingdon-on-Thames: Routledge.

Odhiambo, E. O. S. (2019). Character and Development Challenges and Opportunities Influencing Anglo-Kenyan Diplomatic Relations. Summerian Journal of Social Science, 2, 170-185.

Odhiambo, E. O. S., Maito, L. T., Kassilly, J., Chelumo, S., Onkware, K., \& Oboka, W. A. (2013). Al-Shabaab Terrorists Propaganda \& the Kenya government Response. International Journal of Humanities \& Social Science, 3, 125-131.

http://www.ijhssnet.com/view.php?u=http://www.ijhssnet.com/journals/Vol_3_No_7 April_2013/14.pdf

Okoth, P.G. (2010). USA, India and Africa During and After the Cold War, Nairobi: University of Nairobi Press.

Okuthe-Oyugi, F. (2012). The Political Federation: Something Must Happen! In I. Waffubwa, \& J. C. Birungi (Eds.), The Drive Towards Political Integration in East Africa (pp. 131-149). Arusha: EAC Secretariat.

Ouchi, J. (2013). Prospects for Free Movement in the East African Community, Regions and Cohesion. Special ISSUE Regions-Without Borders? Regional Convergence, Migration, and Social Protection in Africa and Europe, 3, 103-122. https://doi.org/10.3167/reco.2013.030306

Palmer, G., \& Morgan, C. (2006). A Theory of Foreign Policy. Upper Saddle River, NJ: Princeton University Press. https://doi.org/10.1515/9781400832644

Patton, M. Q. (2002). Qualitative Research and Evaluation Methods (3rd ed.). Thousand Oaks, CA: Sage Publications Inc.

Pichon, E. (2018). Economic Partnership Agreement with the East African Community. International Agreements in Progress, European Parliament Service. https://www.europarl.europa.eu/RegData/etudes/BRIE/2018/620218/EPRS_BRI(2018)6 20218_EN.pdf

Prakash, A., \& Hart, J. A. (2000). Indicators of Economic Integration. Global Governance (Brill), 6, 95-114. https://doi.org/10.1163/19426720-00601007

Randall, L. S. (1998). Deadly Imbalances: Tripolarity and Hitlers Strategy of World Con- 
quest (267 p). New York: Columbia University Press.

Roberts, S. (2017). Competition, Regional Integration and Inconclusive Growth in Africa: A Research Agenda. In J. Klaaren, S. Roberts, I. Valodia, \& W. Simbanengani (Eds.), Competition Law and Economic Regulations in Southern Africa: Addressing Market Power in Southern Africa (pp. 263-287). Johannesburg: Wits University Press. https://doi.org/10.18772/22017070909.17

Rose, G. (1998). Review: "Neoclassical Realism and Theories of Foreign". World Politics, 51, 144-172. http://www.jstor.org/stable/25054068 https://doi.org/10.1017/S0043887100007814

Schiff, M., \& Winters, A. (2003). Regional Integration and Development. Washington, DC: IBRD/The World Bank and Oxford University Press.

Severino, R. (2006). Southeast Asia in Search of an ASEAN Community: Insights from the Former ASEAN Secretary General. Singapore: Institute of Southeast Asian Studies. https://doi.org/10.1355/9789812305671

Thomas, J. C. (1996). Useful Adversaries: Grand Strategy, Domestic Mobilization, and Sino-American Conflict, 1947-1958 (319 p). Princeton: Princeton University Press.

Velde, D. W. (2011). Regional Integration, Growth and Convergence. Journal of Economic Integration, 26, 1-28. https://doi.org/10.11130/jei.2011.26.1.1

Wasike, S., \& Odhiambo, E. O. S. (2016). A Critique of the Usefulness of Theories in Explaining Socio-Political Phenomenon. Asian Journal of Basic and Applied Sciences, 3, 29-33.

William, C. W. (1993). The Elusive Balance: Power and Perceptions during the Cold War (317 p). Ithaca: Cornell University Press.

Williams, M. C. (2004). Why Ideas Matter in International Relations: Hans Morgenthau, Classical Realism, and the Moral Construction of Power Politics. International Organisation, 58, 633-665. https://doi.org/10.1017/S0020818304040202

Wolforth, W. (2012). Realism and Foreign Policy. In S. Smith, A. Hadfield, \& T. Dunne (Eds.), Foreign Policy: Theories, Cases, Actors (2nd ed., pp. 35-53). Oxford: Oxford University Press. 